\title{
A Study on the Aging Behavior of Al6061 Composites Reinforced with $\mathrm{Y}_{2} \mathrm{O}_{3}$ and TiC
}

\author{
Chun-Liang Chen * and Chen-Han Lin \\ Department of Materials Science and Engineering, National Dong Hwa University, Hualien 97401, Taiwan; \\ 610222013@ems.ndhu.edu.tw \\ * Correspondence: chunliang@mail.ndhu.edu.tw; Tel.: +886-3-8634205
}

Academic Editor: Hugo F. Lopez

Received: 12 October 2016; Accepted: 3 November 2016; Published: 4 January 2017

\begin{abstract}
The reinforcement particles play important roles in determining microstructural development and properties of Al6061 composites. In the present work, the aging behavior of Al6061 reinforced with $\mathrm{Y}_{2} \mathrm{O}_{3}$ and $\mathrm{TiC}$ particles produced via mechanical alloying are investigated. The results indicate that the peak-aged Al6061 alloy without reinforcement demonstrates the highest hardness, which corresponds to the formation of the $\mathrm{Mg}-\mathrm{Si}$ precipitates. However, precipitation formation is not observed in the case of the Al6061 composites, which can be attributed to the fact that the Mg-Si clusters and GP zones are inhibited by the presence of the reinforcement particles. The solute elements segregate in the complex oxides or carbides and contribute to only a slight increase in hardness.
\end{abstract}

Keywords: aging behavior; mechanical alloying; A16061; composite; precipitation

\section{Introduction}

Al6061 alloys exhibit high corrosion resistance, excellent formability, and a high strength-to-weight ratio [1-3]. They are promising candidates for structural materials in the automotive, aircraft, military, and marine industries. Al6061 metal matrix composites (MMCs) have recently attracted considerable interest due to higher specific strength at high temperature, good fatigue performance, high stiffness, and excellent wear resistance [4-9]. Reinforcement particles play an important role in determining the properties of materials. It has been reported that the presence of nanoparticles enhances strength and plasticity by interacting with dislocations, while simultaneously retarding grain growth [10,11]. In a previous work [12], we have studied Al6061 composites reinforced with $\mathrm{Y}_{2} \mathrm{O}_{3}$ and TiC. The formation of intermetallic compounds and complex oxide dispersoids associated with reinforcement particles-matrix interaction was investigated, and the results demonstrated that a complicated crystal structure of the $\mathrm{Y}_{2}(\mathrm{Al}, \mathrm{Si})_{2} \mathrm{O}_{7}$ phase was found in the Al6061- $\mathrm{Y}_{2} \mathrm{O}_{3}$ composite. The addition of $\mathrm{Y}_{2} \mathrm{O}_{3}$ can provide nucleation sites to facilitate the formation of intermetallic compounds and complex oxide particles [12]. In the case of the Al6061-TiC composite, the TiC particles can act as a milling agent that helps refine the matrix particles and greatly enhances the reactivity of the mixed components, facilitating the formation of iron-rich intermetallic compounds [12]. The Al6061 composites demonstrate a pronounced increase in hardness (about 50\%) compared with the Al6061 alloy [12]. In the present work, we further investigate the effect of the aging behavior of the Al6061 and Al6061 composites. It is important to understand the role of the reinforcement particles and how they influence precipitation. During aging treatment, metastable $\mathrm{Mg}-\mathrm{Si}$ precipitations are formed and the Mg:Si atomic ratio can be altered at different stages of the precipitation evolution, which can be correlated to the mechanical performance of Al6061 alloys. Although there are some studies on the aging behavior of Al-based composite materials [13-16], there is a limited amount of research work reporting the effect of reinforcement particles on the formation of precipitates of Al6061- $\mathrm{Y}_{2} \mathrm{O}_{3}$ and Al6061-TiC composites during aging treatment. Therefore, in this paper, the features of non-reinforced 
Al6061 and reinforced-Al6061 from the supersaturated to the peak time state have been clarified using TEM electron microscopy. The interface between reinforcements and the A16061 matrix and how they control an accelerated aging kinetic in the Al6061 composites will also be discussed.

\section{Materials and Methods}

An Al6061 alloy was used as the composite matrix with a particle size of 44-62 $\mu \mathrm{m}$. Reinforcement particulates used were the yttrium oxide $\left(\mathrm{Y}_{2} \mathrm{O}_{3}\right)$ powder of $99.99 \%$ purity with a particle size in the range $20-50 \mathrm{~nm}$, and titanium carbide (TiC) powder of $99.50 \%$ purity with a particle size range of $40-50 \mu \mathrm{m}$. The three different model materials were fabricated by mechanical alloying (Al6061 alloy, Al6061 composite reinforced with $2 \mathrm{wt} \% \mathrm{Y}_{2} \mathrm{O}_{3}$, and Al6061 composite reinforced with $2 \mathrm{wt} \% \mathrm{TiC}$ ). The mechanical alloying process was carried out using a planetary ball mill (Retsch PM 100, RETSCH, Germany) with a speed of $350 \mathrm{rpm}$ under an argon atmosphere. Milling experiments were performed by using a hardened stainless steel grinding medium with a ball-to-powder ratio of 10:1. The process control agent (PCA) stearic acid was used to inhibit agglomeration of powders during ball milling. The mechanically alloyed powders were consolidated into green compacts with a pressure of $350 \mathrm{MPa}$ and were then further sintered in a mixed hydrogen-argon atmosphere at $600{ }^{\circ} \mathrm{C}$ for $2 \mathrm{~h}$. The Al6061 alloy and Al6061 composites were solution treated at $550{ }^{\circ} \mathrm{C}$ in a furnace for $2 \mathrm{~h}$ and were water quenched at room temperature. All specimens were then aged at room temperature (T4 treatment). Artificial aging (T6 treatment) was carried out at $160{ }^{\circ} \mathrm{C}$ in an oil bath. The age-hardening curves of the Al6061 composite were characterized using Vickers hardness measurements performed at room temperature using a load of $1 \mathrm{~kg}$ for $15 \mathrm{~s}$. The microstructure of the Al6061 composite specimens at different aging stages (solution treatment, peak aging, and over-aging) was examined using a Hitachi-4700 SEM (HITACHI, Tokyo, Japan). Precipitate formation of the peak-aged Al6061 composites was then further investigated on a FEI Tecnai F20 G2 Field Emission Gun TEM (FEI, Hillsboro, OR, USA).

\section{Results and Discussion}

\subsection{Aging Hardness}

In order to understand the aging behavior of the model materials, Vickers hardness was measured in the Al6061 alloy (non-reinforcement) and the Al6061 composites (reinforcements of $\mathrm{Y}_{2} \mathrm{O}_{3}$ and TiC) aged for different times at $160{ }^{\circ} \mathrm{C}$. The age hardening curves of the materials with $\mathrm{T} 6$ treatment are shown in Figure 1. The peak aging hardness of the Al6061 alloy was achieved after aging up to $18 \mathrm{~h}$ (Figure 1A). This shows about a 66\% increase in hardness from the supersaturated solid solution status to the peak aging (123.3 HV). In comparison with the Al6061 composites, the age hardening curve of the Al6061- $\mathrm{Y}_{2} \mathrm{O}_{3}$ composite demonstrates that the peak hardness ( $96.4 \mathrm{HV}$ ) was obtained after aging for $13 \mathrm{~h}$ as shown in Figure 1B. In addition, the aging peak of the Al6061-TiC composite sample was revealed at $8 \mathrm{~h}$ of aging $\left(75.8 \mathrm{HV}\right.$ ) (Figure 1C). The hardness increment of the Al6061- $\mathrm{Y}_{2} \mathrm{O}_{3}$ and the Al6061-TiC composites at the aging peak is about $22 \%$ and $15 \%$, respectively, which are much smaller than that of the Al6061 alloy. However, the hardness of the Al6061 alloy decreased much faster than that of Al6061 composites in the over-aging period. On the other hand, it can be clearly seen that the time required to achieve the aging peak for the Al6061 composites is shorter than that of the Al6061 alloy. These results imply that the formation of precipitates can significantly influence the aging behavior of the model materials. The aging hardness profiles of the materials with T4 treatment are shown in Figure 2. The Al6061 alloy has a significant increase in hardness of about $20 \%$ after the solution heat treatment for $24 \mathrm{~h}$ (Figure 2A). However, the aging hardening curves of the Al6061- $\mathrm{Y}_{2} \mathrm{O}_{3}$ and Al6061-TiC composites with $\mathrm{T} 4$ treatment only demonstrate a minor increase in hardness about $5 \%-7 \%$ after the solution heat treatment for $12 \mathrm{~h}$ (Figure $2 \mathrm{~B}, \mathrm{C}$ ). The results of age hardening also imply that the addition of reinforcement particles plays a major role in accelerating 
the aging process and affecting the formation of precipitates. The precipitation mechanism will be further discussed and investigated in more detail in the following TEM section.

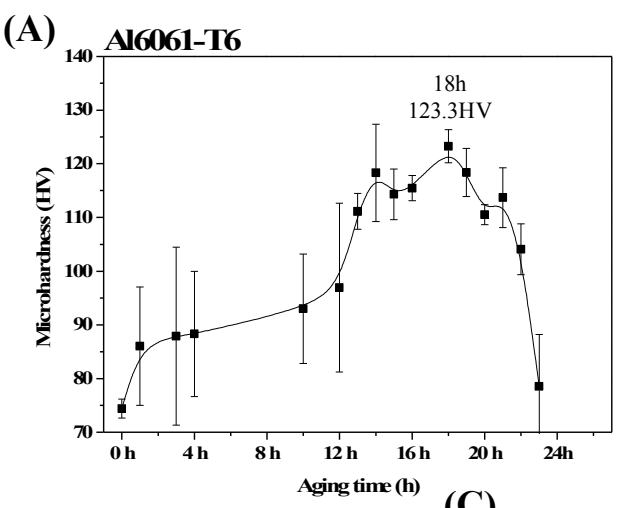

(B)

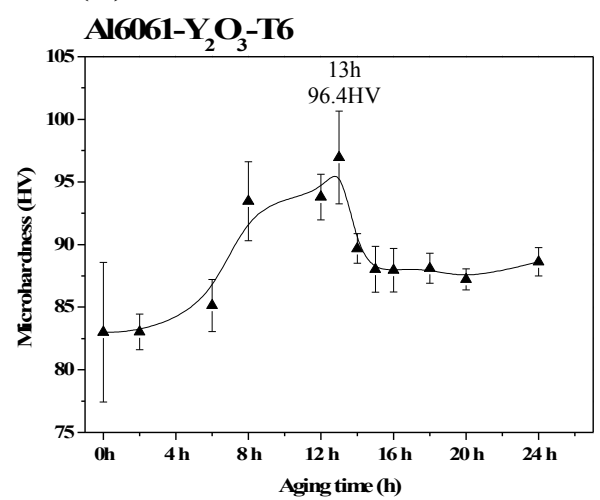

(C)

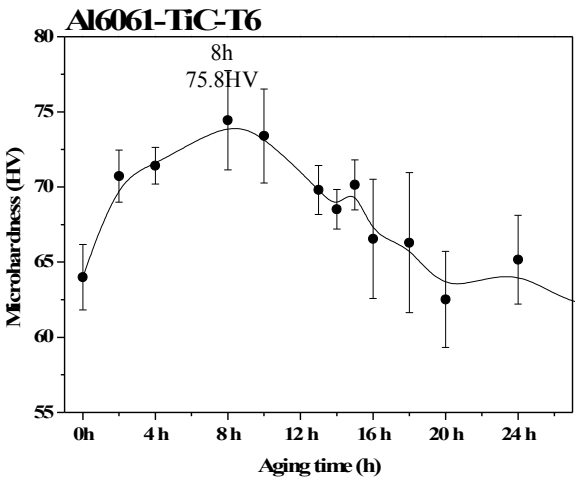

Figure 1. Artificial aging hardening curves of (A) Al6061 alloy; (B) Al6061- $\mathrm{Y}_{2} \mathrm{O}_{3}$; and (C) Al6061-TiC composites at different aging times.

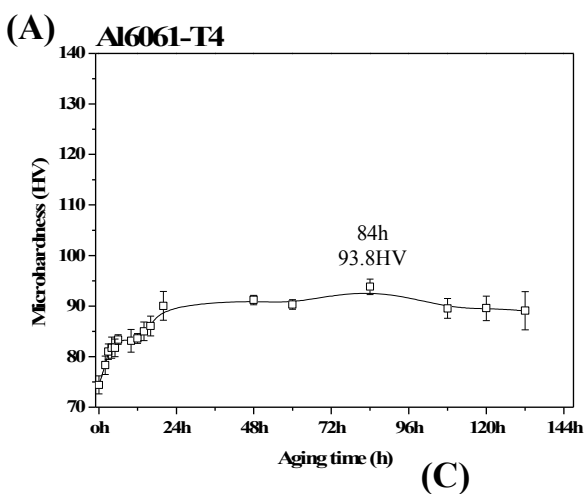

(B)

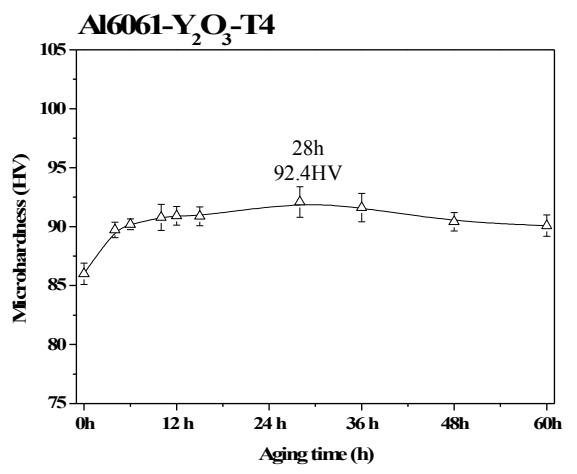

(C)

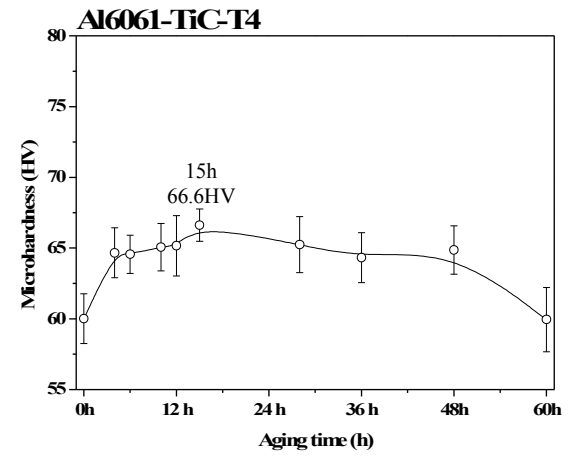

Figure 2. Natural aging hardening curves of (A) Al6061 alloy; (B) Al6061- $\mathrm{Y}_{2} \mathrm{O}_{3}$; and (C) Al6061-TiC composites at different aging times. 


\subsection{Evolution of Microstructure}

\subsubsection{SEM Observation}

The microstructure of the Al6061 alloy and Al6061 composites at the different stages of T6 treatment was further studied. Figure 3 shows the SEM images of the Al6061, Al6061- $\mathrm{Y}_{2} \mathrm{O}_{3}$, and Al6061-TiC samples after solid solution treatment and quenching. In this case, the materials are quenched to keep the material in a supersaturated solid solution state. The Al6061 alloy sample without added reinforcements is shown in Figure 3A; however, a large number of reinforcement particles can be seen uniformly distributed throughout the Al6061- $\mathrm{Y}_{2} \mathrm{O}_{3}$ and Al6061-TiC composites, as shown in Figure 3B,C. Microstructures of the Al6061 alloy and Al6061 composites at the peak aging stage are shown in Figure 4. A clear matrix was also observed in the Al6061 alloy, and the reinforcement particles were again uniformly distributed in the Al6061- $\mathrm{Y}_{2} \mathrm{O}_{3}$ and Al6061-TiC composites. It should be noted that, at the peak aging stage, different types of needle/rod-shaped precipitates of MgxSiy would form within the Al matrix. However, the formation of precipitates would be only nano-sized, and these cannot be easily observed by SEM; therefore, the precipitation evolution of the Al6061 model materials during aging will be further investigated by TEM analysis. The microstructure of over-aged Al6061 samples can also be seen in Figure 5, and this demonstrates that there are a few intermetallic compounds that formed in the microstructure of the Al6061 alloy (Figure 5A). Moreover, there seems to be a coarsening of the reinforcement particles of the Al6061 composites as shown in Figure 5B,C. In the case of the Al6061- $\mathrm{Y}_{2} \mathrm{O}_{3}$ composite sample, the distribution of the reinforcement particles became non-uniform in the matrix, as shown in Figure 5B. It should be noted that the crystal structure of an initial $\mathrm{Y}_{2} \mathrm{O}_{3}$ reinforcement particle in the Al6061 composite can be modified during processing. In an earlier work [12], it was proposed that high-energy ball milling can facilitate a solid-state reaction between the $\mathrm{Y}_{2} \mathrm{O}_{3}$ particles and the Al6061 matrix, and a subsequent sintering processing promotes the formation of the complex Al-Si-Y-O-based oxide particle, which has been identified as the $\mathrm{Y}_{2}(\mathrm{Al}, \mathrm{Si})_{2} \mathrm{O}_{7}$ phase. In the case of the present study, the reinforcement particles played a crucial role in altering the diffusion of the solute elements in the Al6061 composites where a particles-matrix interaction can result in microstructural changes corresponding to different aging behaviors.
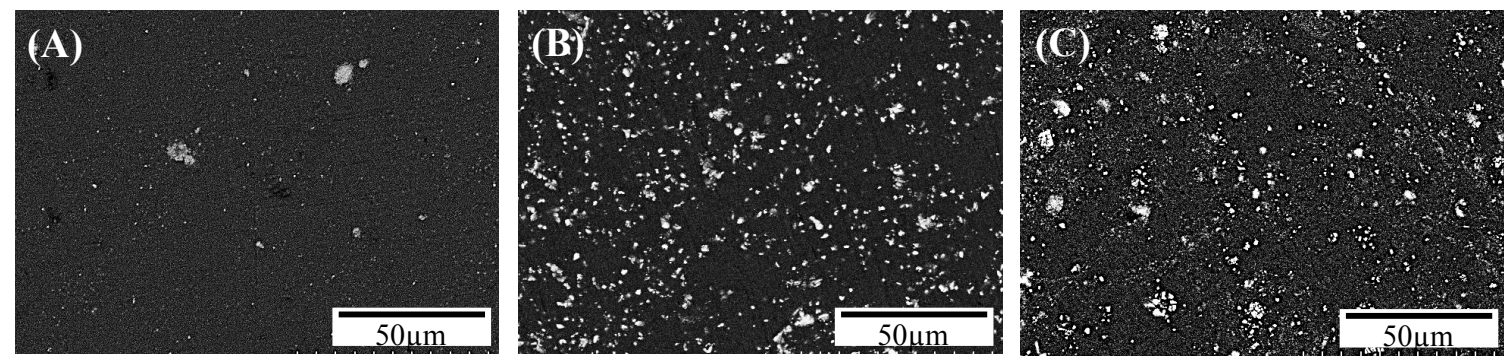

Figure 3. SEM images of (A) Al6061 alloy; (B) Al6061- $\mathrm{Y}_{2} \mathrm{O}_{3}$; and (C) Al6061-TiC composites after solid solution treatment and quenching.
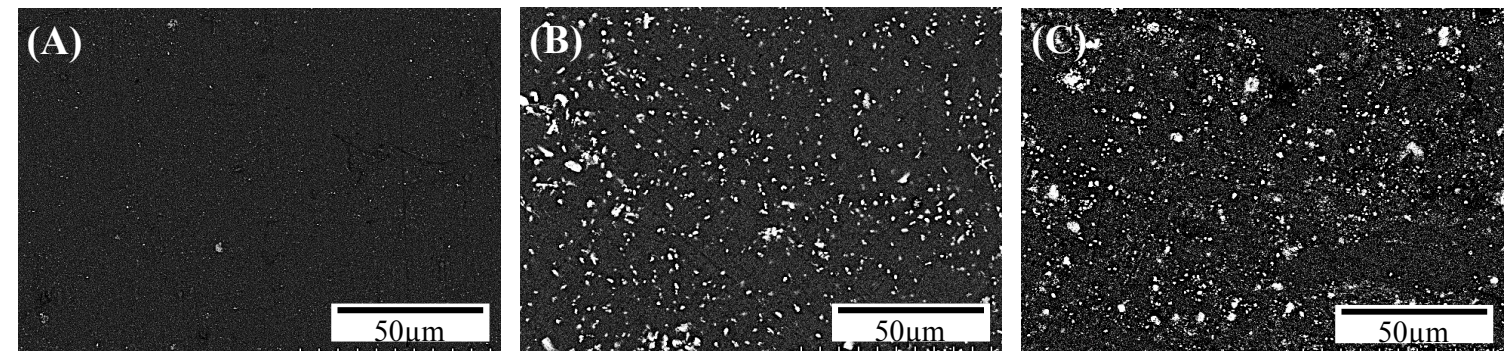

Figure 4. SEM images of (A) Al6061 alloy; (B) Al6061- $\mathrm{Y}_{2} \mathrm{O}_{3}$; and (C) Al6061-TiC composites at peak aging condition. 

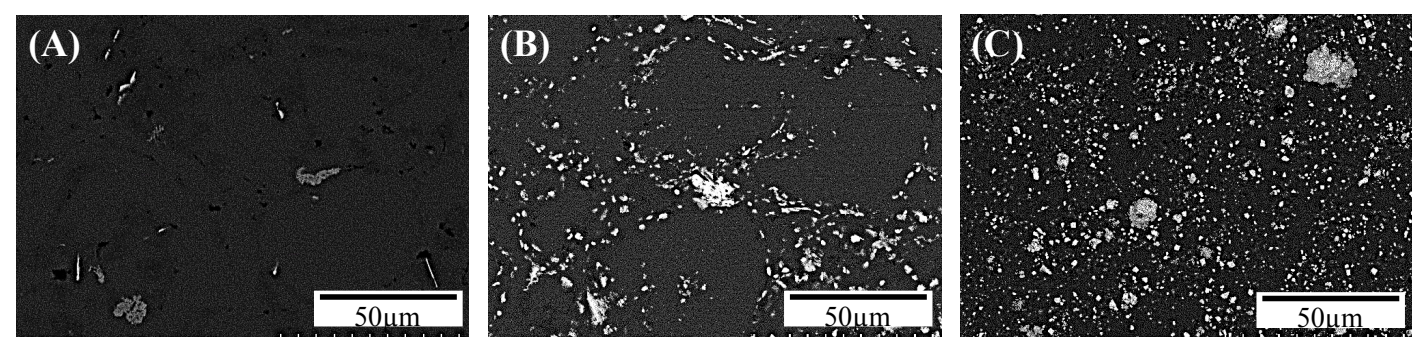

Figure 5. SEM images of (A) Al6061 alloy; (B) Al6061- $\mathrm{Y}_{2} \mathrm{O}_{3}$; and (C) Al6061-TiC composites at over-aging condition.

\subsubsection{TEM Investigation}

TEM was further used to understand the precipitation evolution of the Al6061 model materials during aging treatment. Figure 6A shows a TEM image of the peak-aged Al6061 alloy sample. A large number of needle-like precipitates were observed in the alloy. These nano-precipitates lined up along the $<100>$ direction of the Al matrix, which correspond to the selected area diffraction (SAD) pattern in Figure 6C. They are most likely to be considered $\beta^{\prime \prime}\left(\mathrm{Mg}_{5} \mathrm{Si}_{6}\right)$ and $\beta^{\prime}\left(\mathrm{Mg}_{9} \mathrm{Si}_{5}\right)$ phases, which are normally observed in Al6061 alloys at peak aged conditions. The evolution of aging on the precipitation behavior of the Al6061 alloy can be described in the following stages. After solution treatment and quench, the $\mathrm{Al}$ matrix experienced a high supersaturation of solute atoms and vacancies. This promoted the formation of clusters of $\mathrm{Mg}$ and $\mathrm{Si}$ atoms from the supersaturated matrix. These are known as GP zones. During aging treatment, the Mg:Si ratio can be altered due to the poor solubility and high diffusibility of $\mathrm{Si}$ in $\mathrm{Al}$ [17]. $\mathrm{Mg}$ can diffuse into the GP zones and increase the Mg:Si ratio as aging time increases. This results in metastable coherent or semi-coherent $\beta^{\prime \prime}\left(\mathrm{Mg}_{5} \mathrm{Si}_{6}\right)$ and $\beta^{\prime}\left(\mathrm{Mg}_{9} \mathrm{Si}_{5}\right)$ precipitates in the peak-aged condition, which finally transform to stable incoherent $\beta\left(\mathrm{Mg}_{2} \mathrm{Si}\right)$ precipitates after over-aging [18].

The microstructure of the over-aged Al6061 alloy is shown in Figure 6B. Fine precipitates were observed inside the grains and lie along the $<100>$ directions of the Al matrix (the SAD pattern in Figure 6D), which might correspond to semi-coherent $\beta^{\prime}\left(\mathrm{Mg}_{9} \mathrm{Si}_{5}\right)$ precipitates. However, precipitate particles grow large at the grain boundary and are believed to be stable incoherent $\beta\left(\mathrm{Mg}_{2} \mathrm{Si}\right)$ precipitates. In addition, a precipitation-free zone (PFZ) was clearly found in the over-aged Al6061 alloy sample, as shown in Figure 6B. This can be attributed to the solute depletion from areas adjacent to the boundaries. The decrease in Mg concentration within the PFZ becomes noticeable with increased aging time, corresponding to the growth of grain boundary precipitates.
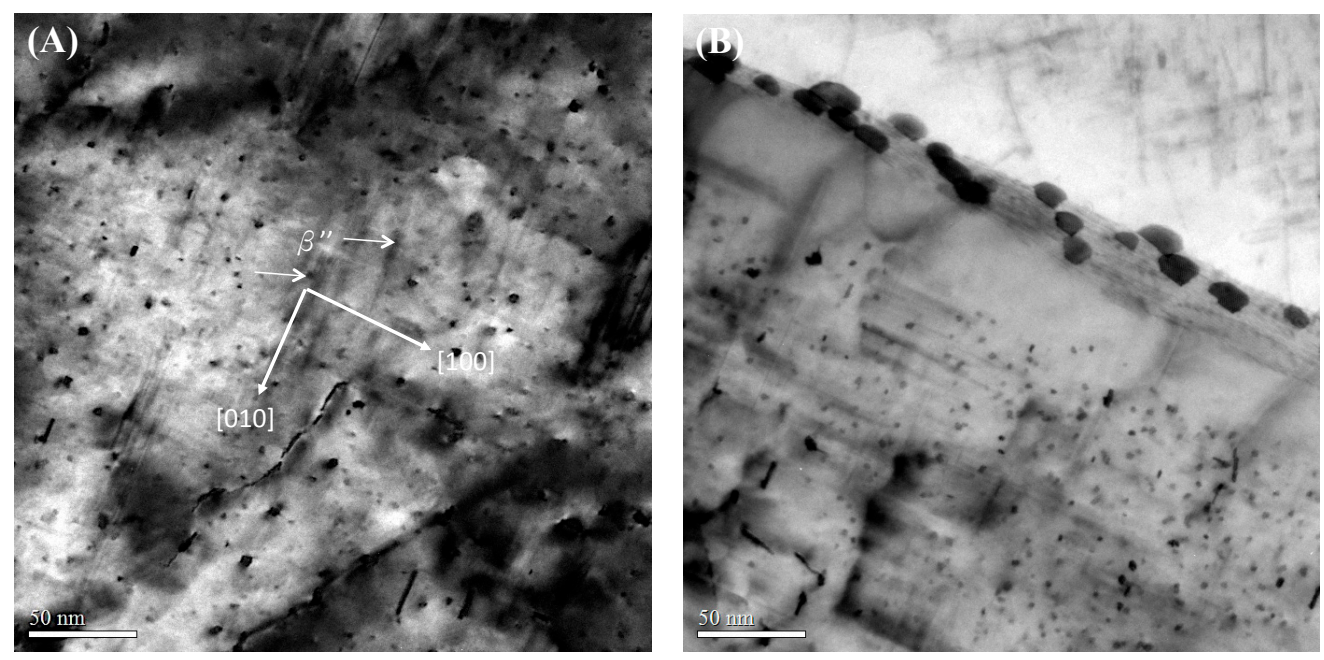

Figure 6. Cont. 

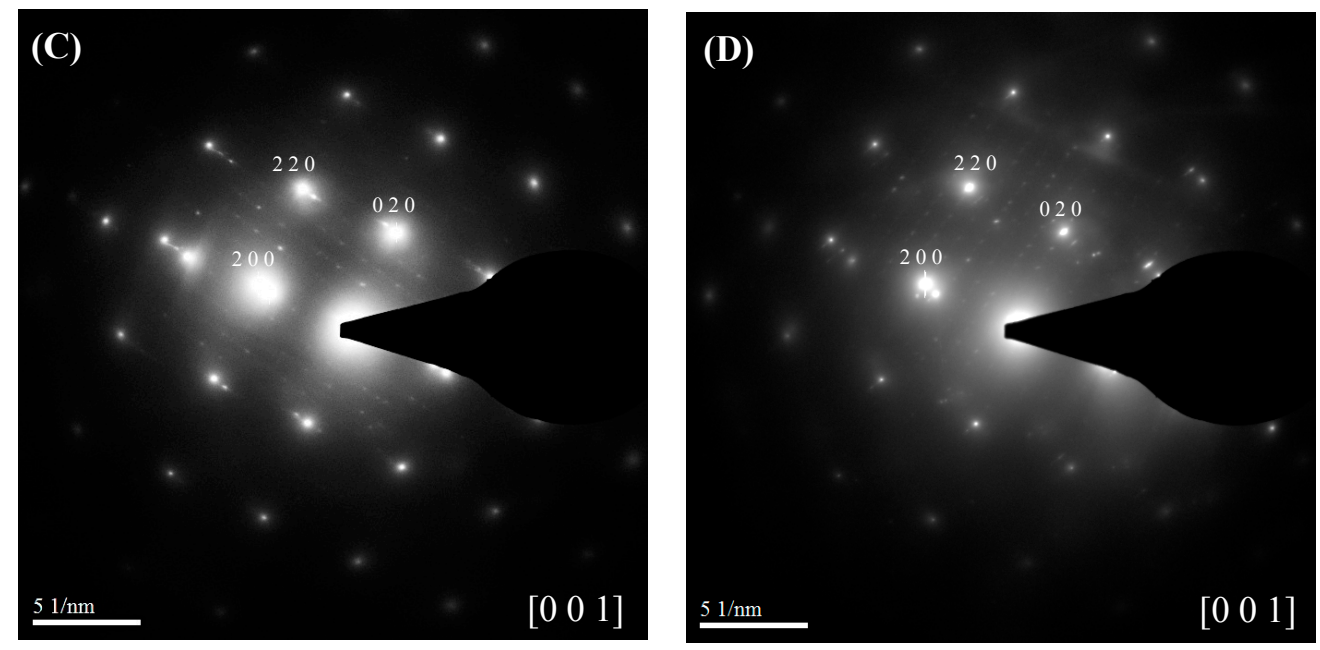

Figure 6. TEM images of (A) the peak-aged and (B) over-aged Al6061 alloys; (C,D) the SAD patterns of $(\mathbf{A})$ and $(\mathbf{B})$ along the $<100>$ direction of the $\mathrm{Al}$ matrix.

Figure 7A,B shows the microstructure of the peak-aged Al6061- $\mathrm{Y}_{2} \mathrm{O}_{3}$ and Al6061-TiC composites, respectively. There was almost no precipitation observed in these two alloy samples. In the Al6061- $\mathrm{Y}_{2} \mathrm{O}_{3}$ sample, a number of dark particles were observed (see the arrows of Figure 7A), and they contain a high level of $\mathrm{Al}, \mathrm{Mg}, \mathrm{Si}, \mathrm{Y}$, and O elements measured by EDS. In early work, it has been reported that $\mathrm{Y}_{2} \mathrm{O}_{3}$ particles in the Al6061 alloy can act as nucleation sites to facilitate the formation of the complex $\mathrm{Al}-\mathrm{Si}-\mathrm{Y}-\mathrm{O}$ oxide particle [12]. The aging process could further promote and accelerate the diffusion of $\mathrm{Mg}$ atoms; therefore, a high concentration of $\mathrm{Mg}$ was found in the complex oxides. In the case of the Al6061-TiC sample, TiC particles containing a small amount of $\mathrm{Al}, \mathrm{Mg}$, and $\mathrm{Si}$ elements were observed in the Al6061 matrix, as indicated by the arrows in Figure 7B.
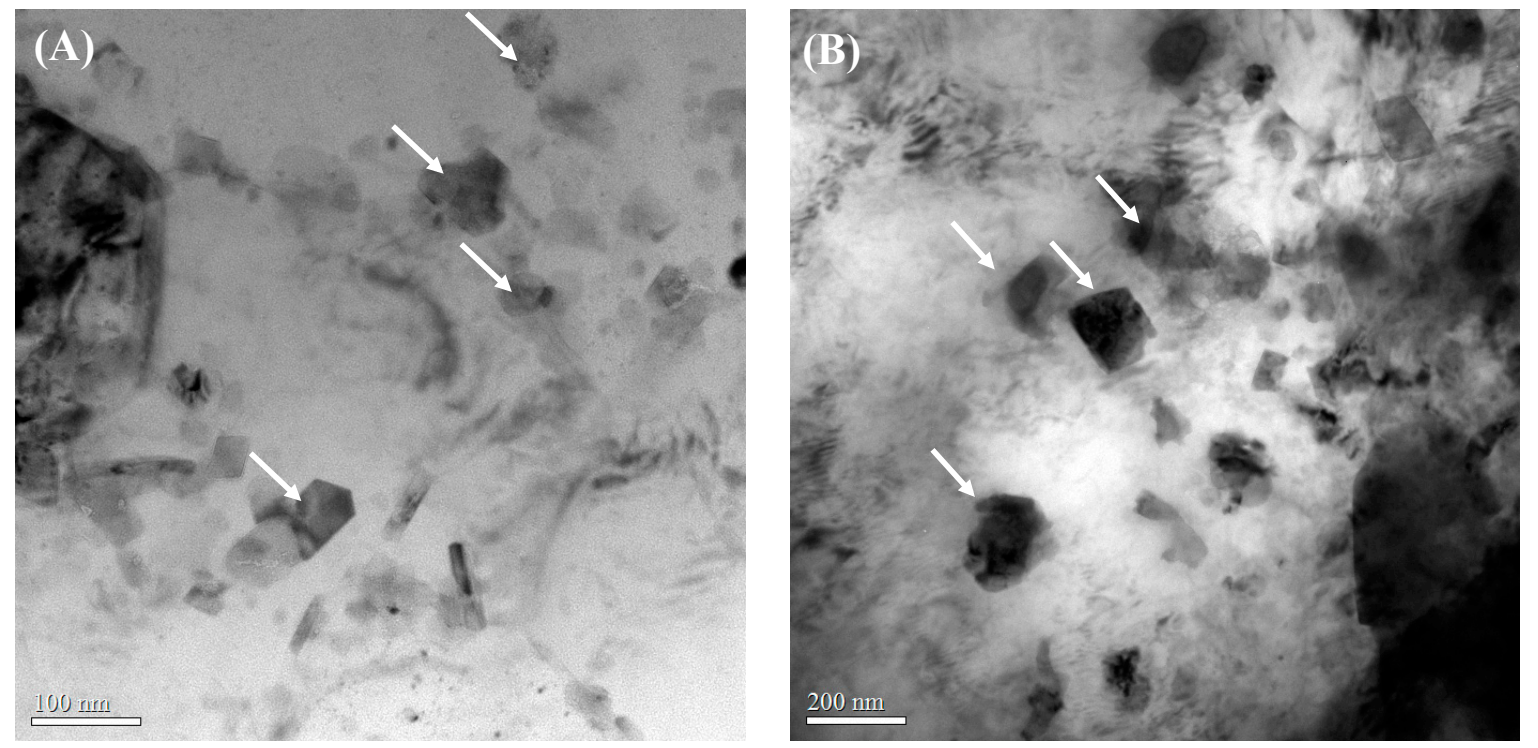

Figure 7. TEM images of (A) the peak-aged Al6061- $\mathrm{Y}_{2} \mathrm{O}_{3}$ and (B) the peak-aged Al6061-TiC composites.

A comparison of the results from the three model materials, the Al6061 has significantly different microstructural characteristics and aging behaviors. The Al6061 alloy was artificially aged at $160{ }^{\circ} \mathrm{C}$ for a prolonged period of time; as a result, the precipitation starts with the formation of $\mathrm{Mg}$ or $\mathrm{Si}$ atomic clusters. However, mechanisms of precipitation hardening can be considerably different 
in the case of the Al6061 composites. The presence of reinforcement particles in the aged-Al6061 composites can effectively impede the formation of GP zones. The mechanical alloying process can facilitate a solid-state reaction between reinforcement particles and the solute elements of $\mathrm{Mg}$ and Si in the Al6061 matrix and generate a large number of vacancies and dislocations in the crystal structure of the milled powders. These vacancies at the interface of oxide or carbide particles and $\mathrm{Al}$ matrix might provide nucleation sites for the solutes where $\mathrm{Mg}$ and $\mathrm{Si}$ could be segregated. The subsequent sintering processing promotes the formation of complex oxides or carbides. As the Al6061 composites are subjected to aging treatments, the solutes are difficult to diffuse back into the $\mathrm{Al}$ matrix. Consequently, the formation of $\mathrm{Mg}-\mathrm{Si}$ clusters and GP zones is inhibited.

In early work, the Al6061- $\mathrm{Y}_{2} \mathrm{O}_{3}$ and Al6061-TiC composites show a pronounced increase in hardness compared with the Al6061 alloy sample without aging treatments [12]. In the present work, the aging precipitation behavior of the model materials can be associated to the age hardening curve. The hardness of the non-reinforced Al6061 alloy significantly increased after T6 treatment, which can be attributed to the formation of fine precipitates as shown in Figure 6. However, the Al6061 composites reinforced with $\mathrm{Y}_{2} \mathrm{O}_{3}$ and TiC particles have only a slight increase in hardness, and the time to peak aging was accelerated. These results can be ascribed to the fact that the $\mathrm{Mg}$-Si precipitation is inhibited by the presence of the reinforcement particles. The amount of $\mathrm{Mg}$ in the $\mathrm{Al}$ matrix is insufficient to form Mg-Si clusters and subsequent $\beta^{\prime \prime}$ and $\beta^{\prime}$ phase formation. Instead, the solute elements can then segregate in the reinforcement particles and the formation of complex oxides and carbides is encouraged, which can only contribute to a slight increase in hardness.

\section{Conclusions}

The aging behavior of the Al6061 alloy, as well as Al6061 composites fabricated by mechanical alloying under T6 and T4 treatments, has been studied. It is important to understand the effects of the presence of reinforcement on the age hardening, precipitation formation, and microstructural change of the Al6061 composites. The results show that the peak aging hardness of the Al6061 alloy shows a significant increase in hardness of about $66 \%$ after solution treatment. However, the Al6061 composites reinforced with $\mathrm{Y}_{2} \mathrm{O}_{3}$ and TiC particles demonstrate only a slight increase in hardness (only $15 \%$ to $22 \%$ ) under T6 treatment. Age hardening of the materials can be associated with the formation of precipitation. TEM investigation shows that a large number of the needle-like precipitates were observed in the peak-aged Al6061 alloy, which line up along the $<100>$ direction of the Al matrix. However, precipitates are hard to form in the peak-aged Al6061 composites. This result could be attributed to the fact that the $\mathrm{Mg}-\mathrm{Si}$ precipitation can be inhibited by the presence of the reinforcement particles. The amount of $\mathrm{Mg}$ in the $\mathrm{Al}$ matrix of the two composite materials is insufficient to form $\mathrm{Mg}-\mathrm{Si}$ clusters and GP zones. The solute elements segregate in the complex oxides or carbides and only contribute to a slight increase in hardness.

Acknowledgments: The authors would like to gratefully acknowledge financial support from the National Science Council of Taiwan under the grant MOST 105-2221-E-259-010. The authors would also like to thank Jian-Yih Wang, National Dong Hwa University, for Al6061 material support.

Author Contributions: C.L.C. conceived and designed the experiments; C.H.L. performed the experiments; C.L.C. and C.H.L. analyzed the data; C.L.C. wrote the paper.

Conflicts of Interest: The authors declare no conflict of interest.

\section{References}

1. Liu, Y.Q.; Cong, H.T.; Wang, W.; Sun, C.H.; Cheng, H.M. AlN nanoparticle-reinforced nanocrystalline Al matrix composites: Fabrication and mechanical properties. Mater. Sci. Eng. A 2009, 505, 151-156. [CrossRef]

2. Ma, Z.Y.; Li, Y.L.; Liang, Y.; Zheng, F.; Bi, J.; Tjong, S.C. Nanometric $\mathrm{Si}_{3} \mathrm{~N}_{4}$ particulate-reinforced aluminum composite. Mater. Sci. Eng. A 1996, 219, 229-231. [CrossRef]

3. Gupta, M.; Surappa, M.K.; Qin, S. Development of Aluminium Based Silicon Carbide Particulate Metal Matrix Composite. J. Mater. Process. Technol. 1997, 67, 94-99. [CrossRef] 
4. Rahimian, M.; Parvin, N.; Ehsani, N.; Mater, A. Investigation of particle size and amount of alumina on microstructure and mechanical properties of Al matrix composite made by powder metallurgy. Mater. Sci. Eng. A 2010, 527, 1031-1038. [CrossRef]

5. Ahamed, H.; Senthilkumar, V. Hybrid Aluminium Metal Matrix Composites and Reinforcement Materials: A Review. Mater. Des. 2012, 37, 182-192. [CrossRef]

6. Nemati, N.; Khosroshahi, R.; Emamy, M.; Zolriasatein, A. Sintering and Hardness Behavior of $\mathrm{Fe}_{-} \mathrm{Al}_{2} \mathrm{O}_{3}$ Metal Matrix Nanocomposites Prepared by Powder Metallurgy. Mater. Des. 2011, 32, 3718-3729. [CrossRef]

7. Fogagnolo, J.B.; Robert, M.H.; Torralba, J.M. Mechanically alloyed AlN particle-reinforced Al-6061 matrix composites: Powder processing, consolidation and mechanical strength and hardness of the as-extruded materials. Mater. Sci. Eng. A 2006, 426, 229-231. [CrossRef]

8. Krizik, P.; Balog, M.; Matko, I.; Sr, P.S.; Cavojsky, M.; Simancik, F. The effect of a particle-matrix interface on the Young's modulus of Al-SiC composites. J. Compos. Mater. 2015, 1-10. [CrossRef]

9. Moghadam, A.D.; Schultz, B.F.; Ferguson, J.B.; Omrani, E.; Rohatgi, P.K.; Gupta, N. Functional Metal Matrix Composites: Self-lubricating, Self-healing, and Nanocomposites-An Outlook. JOM 2014, 66, 872-881. [CrossRef]

10. Zhang, Z.; Topping, T.; Li, Y.; Vogt, R.; Zhou, Y.; Haines, C.; Paras, J.; Kapoor, D.; Schoenung, J.M.; Lavernia, E.J. Mechanical behavior of ultrafine-grained Al composites reinforced with B4C nanoparticles. Scr. Mater. 2011, 65, 652-655. [CrossRef]

11. Li, Y.; Zhang, Z.; Vogt, R.; Schoenung, J.M.; Lavernia, E.J. Boundaries and interfaces in ultrafine grain composites. Acta Mater. 2011, 59, 7206-7218. [CrossRef]

12. Chen, C.-L.; Lin, C.-H. Effect of $\mathrm{Y}_{2} \mathrm{O}_{3}$ and $\mathrm{TiC}$ Reinforcement Particles on Intermetallic Formation and Hardness of Al6061 Composites via Mechanical Alloying and Sintering. Metall. Mater. Trans. A 2015, 46, 3687-3695. [CrossRef]

13. Li, B.; Zeng, B.L.H.; Fan, W.; Bai, Z. Effect of aging on interface characteristics of Al-Mg-Si/SiC composites. J. Alloy. Compd. 2015, 649, 495-499. [CrossRef]

14. Maisonnette, D.; Suery, M.; Nelias, D.; Chaudet, P.; Epicier, T. Effects of heat treatments on the microstructure and mechanical properties of A 6061 aluminium alloy. Mater. Sci. Eng. A 2011, 528, 2718-2724. [CrossRef]

15. Rao, P.N.; Singh, D.; Brokmeier, H.-G.; Jayaganthan, R. Effect of ageing on tensile behavior of ultrafine grained Al6061 alloy. Mater. Sci. Eng. A 2015, 641, 391-401. [CrossRef]

16. Dong, R.; Yang, W.; Yu, Z.; Wu, P.; Hussain, M.; Jiang, L.; Wu, G. Aging behavior of 6061Al matrix composite reinforced with high content $\mathrm{SiC}$ nanowires. J. Alloy. Compd. 2015, 649, 1037-1042. [CrossRef]

17. Lang, P.; Karadeniz, E.P.; Falahati, A.; Kozeschnik, E. Simulation of the effect of composition on the precipitation in 6xxx Al alloys during continuous heating DSC. J. Alloy. Compd. 2014, 612, 443-449. [CrossRef]

18. Vissers, R.; van Huis, M.A.; Jansen, J.; Zandbergen, H.W.; Marioara, C.D.; Andersen, S.J. The crystal structure of the $\beta^{\prime}$ phase in Al-Mg-Si alloys. Acta Mater. 2007, 55, 3815-3823. [CrossRef] 